\title{
Dynamic Analysis of the Rental Prices of Long-Rental Apartments and Ordinary Rental Housing Based on the Impact of Long-Rental Apartment Enterprises' Competitive Behaviors
}

\author{
Lingling Mu, Xiangyu Qin (D), and Yaoyao Wang \\ School of Economics and Management, Hebei University of Technology, Tianjin 300401, China \\ Correspondence should be addressed to Xiangyu Qin; 991685848@qq.com
}

Received 24 August 2020; Revised 30 March 2021; Accepted 18 April 2021; Published 29 April 2021

Academic Editor: Sundarapandian Vaidyanathan

Copyright (c) 2021 Lingling Mu et al. This is an open access article distributed under the Creative Commons Attribution License, which permits unrestricted use, distribution, and reproduction in any medium, provided the original work is properly cited.

\begin{abstract}
This paper addresses the issue of the impact of the competitive behaviors of long-rental apartment firms on the rents of long-rental apartments and ordinary rental housing and introduces a dynamic gaming approach to the housing rental market domain to reveal changes in the long-term complexity of rents of long-rental apartments and ordinary rental housing caused by the competitive behavior of long-rental apartment firms. Through numerical simulation, it is found that the adoption of smaller rent adjustment strategies by firms is important for maintaining system stability, while the changes in reference effect behavior of landlords and service quality and differences in demand share have moderating effects on system stability. The enhanced reference effect of landlords, the improvement of service quality, and the increase of the difference in demand share between the two longrental apartments help to mitigate the disruption of system stability by the increase of the adjustment factor of the firms. The decentralized long-lease apartment firms, which occupy a higher proportion of the market, are able to exert a major impact on the rent of general rental housing by taking advantage of the market, while the difference in the demand share between the two firms is the main reason for the change in the rent of long-rental apartments.
\end{abstract}

\section{Introduction}

Since 2016, the siphoning off of China's developed regions has brought about a significant increase in the speed and size of population movements [1], resulting in a sharp rise in house prices in first- and second-tier cities. Commodity housing prices have gradually become detached from the purchasing power of ordinary people. In order to ease housing tensions, the Chinese Communist Party's Nineteenth Congress proposed to speed up the establishment of a multibody supply and multichannel security housing system [2]. Its immediate objective is to improve the imbalance in the rental and sale structure of the housing market by vigorously developing the housing rental market, so that all people can have places to live [3]. However, in recent years, rents in first-tier cities have increased more sharply than in previous years [4]. According to data from the China Real Estate Association official website in Figure 1, the year-onyear continuous upward trends in the rental price indexes in
Shenzhen and Beijing have both reached 36 months as of December 2019. With rents rising sharply, some low- and middle-income people are lamenting that the pressure to live has shifted to be unable to afford renting a home. Why have rents changed so much in recent years? Scholars have conducted a qualitative analysis of the causes of the recent rent increases. Firstly, the shortage of housing in the rental market has led to a shortage of total supply, as well as an imbalance in the supply structure [5]. Secondly, the entry of long-term rental flat companies into the housing rental market in recent years has had an impact on the overall price of the rental market [6]. These include (1) long-rental apartment enterprises have become important suppliers of supplying rental services, because of their information and capital advantages. Several large rental enterprises may form a regional monopoly competition pattern, which eventually affect the supply of rental services and prices. (2) Long-term apartment companies choose to offer rental services in areas with good geographical conditions and amenities. Therefore, 


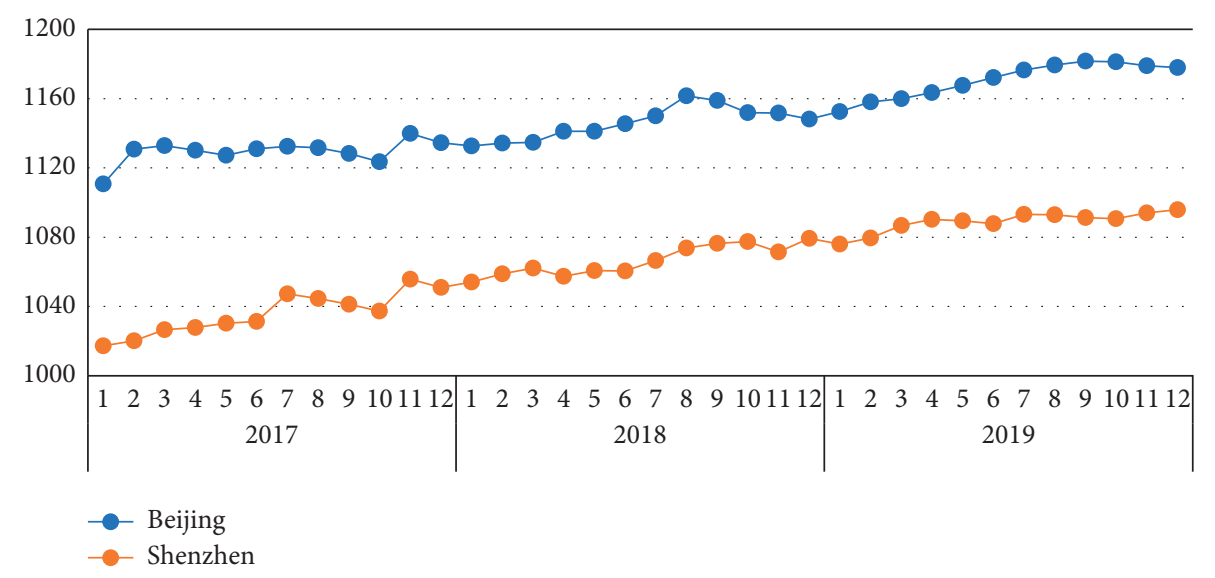

Figure 1: Residential leasing price index of Beijing and Shenzhen, 2017-2019.

ordinary rental housing in this region has the same geographical advantages as long-rental apartments, so the rental price of long-rental apartments has a reference price effect on the landlords' rents. For these reasons given by the abovementioned scholars, the study of the following issues is of great practical relevance. (1) How does competitive behavior among long-rent apartment enterprises affect rent levels? (2) How does the landlords' reference price affect rent levels?

The static expectations approach implies that decisions for the next period are made considering only the optimal strategy for the current period, requiring decision makers to fully understand the market. In reality, market information is often incomplete, and there is information distortion or information asymmetry in many cases. Therefore, a dynamic game model based on bounded rational decision is needed to illustrate the results of long-term game. A game process based on bounded rational considers interactions between groups as dynamic processes based on changing contexts. These interactions can be nonlinear. Nonlinear systems differ from linear systems in that they exhibit randomness even in the absence of external random effects. Intrinsic stochasticity makes long-term economic behavior complex and unpredictable as the system evolves over time. The combination of chaos theory and game theory helps to analyze the changes in complexity that occur in the game system due to the evolution of the game over a long period of time by each subject's behavior. Therefore, in order to reveal the complex changes in rent levels caused by the behaviors of long-rent apartment firms and landlords over time, this paper combines chaos theory and game theory to provide an intrinsically logically consistent theoretical analysis of the problems raised earlier.

Oligopoly is a common phenomenon in economic markets, where each vendor has a strong control over prices and price adjustments by one vendor can have an impact on price movements throughout the industry [7]. The study of the dynamics of price games between manufacturers first emerged in oligopolistic markets [8-10]. To be more realistic, scholars have studied the heterogeneity of oligarchs; for example, the level of information processed by firms is different and firms may adopt limited rationality [11], adaptive expectations [12], and naive rationality [13] to adjust prices. Fan et al. [14] studied a dual oligopoly game with heterogeneity, where players with finite rationality adjust prices according to local estimates of their marginal profits in the previous period, and players with plain expectations adjust prices according to market prices in the previous period by maximizing expected profits. It has been found that the speed of price adjustment by players with limited rationality alters the stability of the equilibrium and leads to chaos in the market structure. The application of chaos theory to the analysis of the dynamic behavior of various stakeholders in the economy and society has become a hot topic of research as the theory of models has been refined, including in markets such as real estate, telecommunications, and real financial market and in supply chains. $\mathrm{Ma}$ and $\mathrm{Mu}$ [15] analyzed the effects of changes in the adjustment coefficients on land prices and house prices using a nonlinear cobweb model. Ma and Zhang analyzed the game of insurance market with three different rational expected oligos [16]. Sambas presented a fractional order model of a financial risk dynamical system and gave the complex behavior of the system [17]. The entire supply chain system involves a number of factors, with information, capital, and logistics flowing between them, which fundamentally makes the supply chain an open and complex system [18]. Hwarng and Xie have discovered that orders or stocks can behave chaotically even when customer demand and lead times are certain [19]. Zhang and Wang studied two dynamic pricing strategies in a two-channel supply chain consisting of manufacturer and retailer, with a focus on the impact of service value on decision making [20]. Wu and Zhang discovered that customers respond to price discounts offered by suppliers and that suppliers adjust prices according to stock holdings, which behaves in a deterministic chaos [21].

It can be seen from the above research that in recent years scholars have gradually used chaos theory to reveal the complexity of the socioeconomic system; however, in recent years the emergence of a new market for long-stay flats in China has led to changes in rents in the housing rental market, which no scholar has analyzed theoretically. Therefore, this paper introduces this analytical approach to 
the field of housing rental market research based on previous studies combining game theory and chaos theory and conducts an internally logical and consistent theoretical analysis based on previous qualitative analysis of the reasons why rents affect the housing rental market, to explore the impact of competitive behavior of long-term rental apartment companies on housing rental market rents.

The structure of this paper is as follows: Section 2 presents a game model in the housing rental market consisting of landlords, long-rent apartment firms, and consumers. Section 3 analyzes the local stability of the Nash equilibrium point of the game system. Section 4 explores the complex changes in the rental price of long-stay apartments and ordinary rental housing due to the competitive behavior of long-stay apartment firms by using numerical simulations. Section 5 draws the conclusions of the paper.

\section{Problem Description and Model Building}

2.1. Problem Description. The long-rental apartments studied in this paper are decentralized long-term rental apartments that are widespread in the housing rental market. Decentralized long-term rental apartments, i.e., rental platforms, obtain properties from scattered landlords, and after standardization or renovation, they are rented out and managed in a unified manner. Long-term rental apartments are able to provide tenants with specialized and regulated rental services compared to the ordinary rental housing provided by landlords. In the operation of long-rental apartments, long-rental apartment enterprises require a large investment of capital. Thus, in the housing rental market, professional rental services are provided mainly by a few large long-term apartment companies. These long-rent apartment companies could form an oligopoly in the longrental apartments market. For example, there are two dominant companies in the long-term rental market that can provide rental services, such as Ziru Apartments and Danke Apartments. Long-term rental apartments exist in locations with convenient transportation and good amenities, and there is a strong demand for consumers in the area. So the rental price of long-rental apartments affects the rental price of landlords in ordinary rental housing. The landlords adjust the rent of their own rented houses with reference to the adjustment of the rent of long-term rental apartments. The composition of the game system is detailed in Figure 2.

2.2. Model Building. Long-rental apartments are able to provide professional and regulated rental services for tenants, so the demand that affects consumers includes not only the level of rent of long-rental apartments but also the service level. In this paper, it is assumed that there are two competing long-stay apartment firms in the market, and according to the Bertrand game model, the demand function can be expressed as

$$
\begin{aligned}
& D_{1}=\theta a-b_{1} p_{1}+d_{1} p_{2}+k_{1} s_{1}-h_{1} s_{2}, \\
& D_{2}=(1-\theta) a-b_{2} p_{2}+d_{2} p_{1}+k_{2} s_{2}-h_{2} s_{1},
\end{aligned}
$$

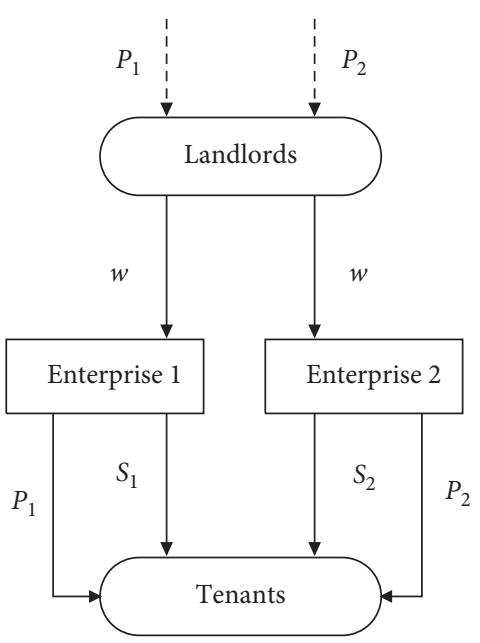

Figure 2: Game system.

where $a$ denotes the potential demand of consumers for long-rental apartments, $\theta$ denotes consumers' share of potential demand for long-rental apartments 1 in the longrental apartment market, $p_{i}$ denotes the rental price of longrental apartments, $b_{i}$ denotes the rental price sensitivity coefficient of long-rental apartments, $d_{i}$ denotes the impact coefficient of the replacement price of long-rental apartments, $k_{i}$ denotes the sensitivity coefficient of the service level of long-rental apartments, $h_{i}$ denotes the impact coefficient of the replacement price of long-rental apartments, and $s_{i}$ denotes the service level of long-rental apartments.

According to the literature $[22,23]$, companies adopt high service standards and pay high service costs which can be expressed as

$$
c_{i}=\frac{\sigma_{i}}{2} s_{i}^{2},
$$

where $\sigma_{i}$ denotes the unit service cost of long-rental apartment companies.

The profit of a long-rent apartment firm is derived from the difference in price earned by long-rent apartment firm renting out long-rent apartments to tenants after receiving the house from the landlord. So, the profit function can be expressed as

$$
\begin{aligned}
& \pi_{1}=\left(p_{1}-w\right) D_{1}-c_{1}, \\
& \pi_{2}=\left(p_{2}-w\right) D_{2}-c_{2},
\end{aligned}
$$

where $w$ represents the rent paid by the long-rent apartment business to the landlord.

The decision of long-rental apartment enterprises is bounded rational. The price adjustment strategy of longrental apartment companies is based on a partial forecast of current marginal profits [24]. This means that if marginal profits are positive in cycle $t$, enterprises will raise their rent levels in cycle $t+1$. Conversely, if marginal profit is negative in cycle $t$, enterprises will be lower their rent levels in cycle $t+1$. The dynamic equation of an enterprise can be expressed as follows: 


$$
\begin{aligned}
& p_{1}(t+1)=p_{1}(t)+\alpha_{1} p_{1}(t) \frac{\partial \pi_{1}}{\partial p_{1}}, \\
& p_{2}(t+1)=p_{2}(t)+\alpha_{2} p_{2}(t) \frac{\partial \pi_{2}}{\partial p_{2}} .
\end{aligned}
$$

The landlords who provide ordinary rental housing readjust the rent of their own rented accommodation with reference to the adjustment of the rent of long-rental apartments. There are two competing long-rental apartments in the housing rental market. The impact of price adjustment to the rents of both long-lease apartments on the price adjustment of ordinary rental housing depends on the potential demand share of the different long-rental apartments in the rental market. The landlords' adjustments of the price of rental housing depend not only on the impact of the price adjustment of the long-rental apartment, but also on its own sensitivity to the rent perception of the long-rental apartment, so the landlords' rental price can be expressed as

$$
\begin{aligned}
p_{s}(t+1)= & p_{s}(t)+\eta\left(\theta\left(p_{1}(t)-p_{1}(t-1)\right)\right. \\
& \left.+(1-\theta)\left(p_{2}(t)-p_{2}(t-1)\right)\right) .
\end{aligned}
$$

According to principal-agent theory, the principal creates a principal-agent relationship with the agent based on the principle of maximizing expected utility. Therefore, the landlord chooses whether to entrust the house to a longrental apartment enterprise for rental based on its utility. This paper assumes that the expected utility of the landlord when the landlord chooses to entrust an agent is $U_{c}$. The expected utility of the landlord depends on the rent $w$ paid by the long-rent apartment enterprise to the landlord and the time cost $t$ obtained when the landlord chooses to entrust an agent. When the entrusting agent is not used, the landlord's expected utility $U_{s}$ is to obtain the rent $p_{s}$ by using its own way of renting.

Therefore, following the principle of utility maximization, the conditions for a landlord to choose to entrust the rental of a house to a long-rental apartment enterprise should satisfy $U_{c}>U_{s}$ which is $w+t \geq p_{s}$. This paper assumes that the rent, the long-rent apartment enterprise pays to the landlord $w$, is $p_{s}-t$. So $w$ can be expressed as

$$
\begin{aligned}
w(t+1)= & w(t)+\eta\left(\theta\left(p_{1}(t)-p_{1}(t-1)\right)\right. \\
& \left.+(1-\theta)\left(p_{2}(t)-p_{2}(t-1)\right)\right),
\end{aligned}
$$

where $w(t)=p_{s}(t)-t$.

Thus, the game dynamics system consisting of the longstay apartment enterprise, the tenants, and the landlords can be expressed as follows:

$$
\begin{aligned}
p_{1}(t+1)= & p_{1}(t)+\alpha_{1} p_{1}(t)\left(b _ { 1 } \left(c_{1}-p_{1}(t)\right.\right. \\
& \left.+w(t))-b_{1} p_{1}(t)+d_{1} p_{2}(t)+a \theta+k_{1} s_{1}-h_{1} s_{2}\right), \\
p_{2}(t+1)= & p_{1}(t)+\alpha_{2} p_{2}(t)\left(b _ { 2 } \left(c_{2}-p_{2}(t)\right.\right. \\
& +w(t))-b_{2} p_{2}(t)+d_{2} p_{1}(t) \\
& \left.+a(1-\theta)+k_{2} s_{2}-h_{2} s_{1}\right), \\
w(t+1)= & w(t)+\eta\left(\theta \left(p_{1}(t)-p_{1}(t-1)\right.\right. \\
& \left.+(1-\theta))\left(p_{2}(t)-p_{2}(t-1)\right)\right) .
\end{aligned}
$$

From the iterative relationship of (6), it can be seen that the rent $w(t+1)$ paid by the enterprise to the landlord in period $t+1$ can be transformed into $w(t+1)=$ $w(0)+\eta \sum_{i=1}^{t}\left(\theta\left(p_{1}(t)-p_{1}(t-1)+(1-\theta)\right)\left(p_{2}(t)-\right.\right.$ $\left.\left.p_{2}(t-1)\right)\right)$.

Thus, the transformed game dynamics system can be expressed as follows:

$$
\begin{aligned}
p_{1}(t+1) & =p_{1}(t)+\alpha_{1} p_{1}(t)\left(\begin{array}{c}
b_{1}\left(c_{1}-p_{1}(t)+w(0)+\eta\left(\theta\left(x_{1}(t)-p_{1}(0)+(1-\theta)\left(x_{2}(t)-p_{2}(0)\right)\right)\right)\right) \\
-b_{1} p_{1}(t)+d_{1} p_{2}(t)++a \theta+k_{1} s_{1}-h_{1} s_{2}
\end{array}\right), \\
p_{2}(t+1) & =p_{1}(t)+\alpha_{2} p_{2}(t)\left(\begin{array}{c}
b_{2}\left(c_{2}-p_{2}(t)+w(0)+\eta\left(\theta\left(x_{1}(t)-p_{1}(0)+(1-\theta)\left(x_{2}(t)-p_{2}(0)\right)\right)\right)\right) \\
-b_{2} p_{2}(t)+d_{2} p_{1}(t)+a(1-\theta)+k_{2} s_{2}-h_{2} s_{1}
\end{array}\right), \\
x_{1}(t) & =p_{1}(t), \\
x_{2}(t) & =p_{2}(t)
\end{aligned}
$$

\section{Game Equilibrium Point and Stability Analysis}

3.1. Equilibrium Point. Based on the definition of fixed point, we make $p_{i}(t+1)=p_{i}(t)$ and $x_{i}(t+1)=x_{i}(t)$ and give four equilibrium points, including three boundary equilibrium points and one Nash equilibrium point. Since the boundary equilibrium point has no point in discussion, we only discuss the Nash equilibrium point of the system $E^{*}=\left(p_{1}^{*}, p_{2}^{*}, x_{1}^{*}, x_{2}^{*}\right)$, where $p_{1}^{*}=x_{1}^{*}, \quad p_{2}^{*}=x_{2}^{*}, \quad p_{1}^{*}$ $=\left(\left(\begin{array}{c}\left(d_{1}-b_{1} \eta(\theta-1)\right)\left(a-a \theta-h_{2} s_{1}+k_{2} s_{2}+b_{2}\left(c 2+w-p_{2}(0) \eta-p_{1}(0) \theta \eta+p_{2}(0) \theta \eta\right)\right) \\ +b_{2}(\theta \eta-\eta+2)\left(a \theta-h_{1} s_{2}+k_{1} s_{1}+b_{1}\left(c_{1}+w-p_{2}(0) \eta-p_{1}(0) \theta \eta+p_{2}(0) \theta \eta\right)\right)\end{array}\right)\right) /$ $\left(b_{1}\left(2 b_{2}(2-\eta)-d_{2} \eta(1-\theta)-d_{1}\left(d_{2}+b_{2} \theta \eta\right)\right)\right), \quad p_{2}^{*}=$

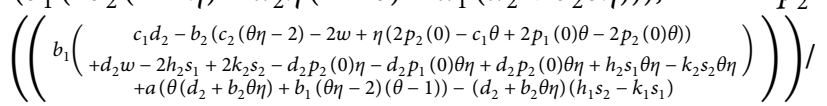


$\left(b_{1}\left(2 b_{2}(2-\eta)-d_{2} \eta(1-\theta)-d_{1}\left(d_{2}+b_{2} \theta \eta\right)\right)\right), w^{*}=w(0)$ $+\eta\left(\theta\left(x_{1}^{*}-p_{1}(0)\right)+(1-\theta)\left(x_{2}^{*}-p_{2}(0)\right)\right)$,

$$
p_{s}^{*}=p_{s}(0)+\eta\left(\theta\left(x_{1}^{*}-p_{1}(0)\right)+(1-\theta)\left(x_{2}^{*}-p_{2}(0)\right)\right) \text {. }
$$

3.2. Nash Equilibrium Point Stability Analysis. The Jury stability criterion is an important way of judging the stability of linear discrete systems. The stability of a discrete system is judged by analyzing the coefficients of its characteristic equation, and the discrete system is stable if all the characteristic roots of the characteristic polynomial lie within the unit circle, which means that the Jury condition is satisfied. Therefore, in order to study the local stability of the equilibrium points, the equilibrium points were brought into the Jacobian matrix.

$$
\begin{aligned}
& J=\left(\begin{array}{cccc}
J_{11} & J_{12} & J_{13} & J_{14} \\
J_{21} & J_{22} & J_{23} & J_{24} \\
1 & 0 & 0 & 0 \\
0 & 1 & 0 & 0
\end{array}\right), \\
& J_{11}=1-2 \alpha_{1} b_{1} p_{1}-\alpha_{1} \frac{\partial \pi_{1}}{\partial p_{1}}, \\
& J_{12}=\alpha_{1} d_{1} p_{1}, \\
& J_{13}=\alpha_{1} b_{1} p_{1} \theta \eta, \\
& J_{14}=\alpha_{1} b_{1} p_{1} \eta(1-\theta), \\
& J_{21}=\alpha_{2} d_{2} p_{2}, \\
& J_{22}=1-2 \alpha_{2} b_{2} p_{2}-\alpha_{2} \frac{\partial \pi_{2}}{\partial p_{2}}, \\
& J_{23}=\alpha_{2} b_{2} p_{2} \theta \eta, \\
& J_{24}=\alpha_{2} b_{2} p_{2} \eta(1-\theta) .
\end{aligned}
$$

The characteristic equation of (10) can be expressed as follows:

$$
f(\lambda)=\lambda^{4}+\mu_{3} \lambda^{3}+\mu_{2} \lambda^{2}+\mu_{1} \lambda+\mu_{0},
$$

making

$$
\begin{aligned}
& g_{1}=1+\mu_{0}+\mu_{1}+\mu_{2}+\mu_{3}, \\
& g_{2}=1+\mu_{0}-\mu_{1}+\mu_{2}-\mu_{3}, \\
& g_{3}=1-\left|\mu_{0}\right|, \\
& g_{4}=\varphi_{3}-\left|\varphi_{0}\right|, \\
& g_{5}=\gamma_{2}-\left|\gamma_{0}\right|,
\end{aligned}
$$

where

$$
\begin{aligned}
& \varphi_{3}=1-\mu_{0}^{2}, \\
& \varphi_{2}=\mu_{3}-\mu_{0} \mu_{1}, \\
& \varphi_{1}=\mu_{2}-\mu_{0} \mu_{2}, \\
& \varphi_{0}=\mu_{1}-\mu_{0} \mu_{3}, \\
& \gamma_{2}=\varphi_{3}^{2}-\varphi_{0}^{2}, \\
& \gamma_{1}=\varphi_{3} \varphi_{2}-\varphi_{1} \varphi_{0}, \\
& \gamma_{0}=\varphi_{3} \varphi_{1}-\varphi_{0} \varphi_{2} .
\end{aligned}
$$

Therefore, the Jury conditions after the equilibrium point is brought in are as follows:

$$
\begin{aligned}
g_{1}= & \alpha_{1} \alpha_{2} p_{1}^{*} p_{2}^{*}\left(4 b_{1} b_{2}-d_{1} d_{2}-2 b_{1} b_{2} \eta-b_{1} d_{2}(1-\theta) \eta-b_{2} d_{1} \theta \eta\right), \\
g_{2}= & 4-2 \alpha_{2} b_{2} p_{2}^{*}(1-\theta) \eta-4 \alpha_{2} b_{2} p_{2}^{*}-2 \alpha_{1} b_{1} p_{1}^{*} \theta \eta-4 \alpha_{1} b_{1} p_{1}^{*}+\alpha_{1} \alpha_{2} p_{1}^{*} p_{2}^{*} \\
& \left(4 b_{1} b_{2}-d_{1} d_{2}-2 b_{1} b_{2} \eta-b_{1} d_{2}(1-\theta) \eta-b_{2} d_{1} \theta \eta\right), \\
g_{3}= & 1, \\
g_{4}= & 1-\alpha_{2} b_{2} p_{2}^{*}(1-\theta) \eta-\alpha_{1} b_{1} p_{1}^{*} \theta \eta+\alpha_{1} \alpha_{2} p_{1}^{*} p_{2}^{*}\left(2 b_{1} b_{2} \eta-b_{1} d_{2}(1-\theta) \eta-b_{2} d_{1} \theta \eta\right), \\
g_{5}= & 2 \alpha_{1} b_{1} p_{1}^{*}-\eta^{2}\left(\alpha_{2}\left(b_{2} p_{2}^{*}\left(\theta+\alpha_{1} p_{1}^{*}\left(2 b_{1}+d_{1} \theta\right)-1\right)-\alpha_{1} b_{1} d_{2} p_{1}^{*} p_{2}^{*}(\theta-1)\right)-\alpha_{1} b_{1} p_{1}^{*} \theta\right)^{2} \\
& +2 \alpha_{2} b_{2} p_{2}^{*}-\eta \alpha_{2} b_{2} p_{2}^{*}\left(\theta+\alpha_{1} p_{1}^{*}\left(2 b_{1}+d_{1}(\theta-1)-\alpha_{1} b_{1} d_{2} p_{1}^{*} p_{2}^{*}(\theta-1)\right)-\alpha_{1} b_{1} p_{1}^{*} \theta\right) \\
& \left(2 \alpha_{1} b_{1} p_{1}^{*}+2 \alpha_{2} b_{2} p_{2}^{*}-2\right)+\alpha_{1} b_{1} p_{1}^{*} \theta \eta-\alpha_{2} b_{2} p_{2}^{*} \eta(\theta-1)-4 \alpha_{1} \alpha_{2} b_{1} b_{2} p_{1}^{*} p_{2}^{*}+\alpha_{1} \alpha_{2} d_{1} d_{2} p_{1}^{*} p_{2}^{*} .
\end{aligned}
$$


According to Jury, the system needs to satisfy $g_{i}>0$ to reach stability, one of which cannot be satisfied and the stability of the system will change.

Proposition 1. The Nash equilibrium point of dynamic gaming is asymptotically stable when the price adjustment factor of the two firms is sufficiently small.

Since $b_{1}>d_{1}, b_{2}>d_{2}$, it can be seen that when $\alpha_{i}$ is positive, $g_{1}>0$ condition is satisfied. When $\alpha_{i}$ is a small enough positive number, $g_{2}>0, g_{3}>0$ conditions are satisfied. When $\alpha_{1}=0, \alpha_{2}=0, g_{5}=0$ are satisfied. Thus, we should think about the linear approximation of $g_{5}\left(\alpha_{1}, \alpha_{2}\right)$ when $\alpha_{1}=0, \alpha_{2}=0$.

$$
\begin{aligned}
g_{5}\left(\alpha_{1}, \alpha_{2}\right) & =g_{5}(0,0)+\frac{\partial y(0,0)}{\partial \alpha_{1}} \alpha_{1}+\frac{\partial y(0,0)}{\partial \alpha_{2}} \alpha_{2}+o\left(\alpha_{1}+\alpha_{2}\right) \\
& =\alpha_{1}\left(2 b_{1} p_{1}^{*}-b_{1} p_{1}^{*} \theta \eta\right)+\alpha_{2}\left(2 b_{2} p_{2}^{*}-b_{2} p_{2}^{*}(1-\theta) \eta\right) .
\end{aligned}
$$

From the above equation, when $\alpha_{i}$ is a sufficiently small positive number, $g_{5}\left(\alpha_{1}, \alpha_{2}\right)>0$ is satisfied, so the Nash equilibrium point is progressively stable.

Proposition 2. When an enterprise's price adjustment factor is small enough, the game system can bifurcate as the price adjustment factor of competing enterprise gradually increases.

We suppose $\alpha_{2}$ is a small enough positive number. According to the stability criterion shown by the proof of Proposition $1, g_{1}>0, g_{3}>0$ is constant. According to $g_{2}=4-2 \alpha_{1} b_{1} p_{1}^{*} \theta \eta-4 \alpha_{1} b_{1} p_{1}^{*}+o(1)$, it can be seen that $g_{2}$ is a monotonic decreasing function about $\alpha_{1}$. We make $g_{2}=$ 0 to get the equation as follows:

$$
\alpha_{1}=\frac{2}{b_{1} p_{1}^{*}(\theta \eta+2)}+o(1) \triangleq \alpha_{1}^{*} .
$$

When $\alpha_{1}=\alpha_{1}^{*}$, the equations as follows are satisfied.

$$
\begin{aligned}
& g_{4} \approx 1-\frac{2 \theta \eta}{(\theta \eta+2)}>0, \\
& g_{5} \approx \frac{8+8 \theta \eta-6 \theta^{2} \eta^{2}}{(\theta \eta+2)^{2}}>0,
\end{aligned}
$$

$\delta$ is assumed to be a positive constant that tends to zero. When $\alpha_{1}=\alpha_{1}^{*}-\delta, g_{i}>0$ is satisfied. At this time, there are an eigenvalue close to and less than 1 , and an eigenvalue close to and greater than -1 in the Jacobi matrix (10). The rest of the eigenvalues fall within the unit circle. The mode of eigenvalues is a continuous function of $\alpha_{1}$. The eigenvalue close to and greater than -1 passing through -1 makes $g_{2}<0$ by $g_{2}=1+\mu_{0}-\mu_{1}+\mu_{2}-\mu_{3}$.

By $g_{2}=1+\mu_{0}-\mu_{1}+\mu_{2}-\mu_{3}$ we know that when $\alpha_{1}$ is increased from $\alpha_{1}=\alpha_{1}^{*}-\delta$ to $\alpha_{1}=\alpha_{1}^{*}+\delta$, an eigenvalue close to and greater than -1 passes through -1 . At this time, $g_{2}$ is less than 0 and the rest of the eigenvalues are within the unit circle. As a result, the stability of the equilibrium point has changed and the system has bifurcated.

\section{Numerical Simulation}

A nonlinear system is so complex that it cannot be derived through traditional logical reasoning. Thus, the following numerical simulations are used in this paper. As the rental price of housing is mainly related to the regional nature of the housing stock, rental area, rental form, and seasonality, long-term rental flats are mainly rented in the form of one bedroom in a shared flat; therefore, the simulation data used in this section are the rental price of one bedroom rented in a shared apartment in Chaoyang District, Beijing. According to the official website of Ziru, a major long-term rental flat operator, on 17 March 2021, the average rental price was RMB 3,284.56/month, while the website of Anjuke showed a rental price of $\mathrm{RMB} 2,461.93 /$ month for ordinary rental housing. The price that a long-term rental company can reasonably charge a landlord for a home should be lower than the price at which ordinary rental housing is rented. Tenants have a stronger degree of access to information about the price of their own rented housing than competitors' prices, and there is fidelity to the housing they have rented, so the price sensitivity factor is greater than the alternative price sensitivity factor. Rents are more easily perceived by tenants than service experiences and therefore the price coefficients relating to rents should be higher than those relating to services.

From the above analysis, the following parameters $a=2$, $\theta=0.5, b_{1}=0.9, b_{2}=0.88, d_{1}=0.7, d_{2}=0.72, h_{1}=0.3$, $h_{2}=0.3, k_{1}=0.5, k_{2}=0.5, s_{1}=1, \sigma_{1}=0.08, \sigma_{2}=0.08$, $p_{s}(0)=2, p_{1}(0)=3.285, p_{2}(0)=3.285$ are assumed in this paper.

The Nash equilibrium point is $p_{1}^{*}=2.69, p_{2}^{*}=2.73$, $p_{s}^{*}=1.92$.

\subsection{The Impact of the Enterprises' Price Adjustment Strategy on} the System. Figures 3(a)-3(c) give the bifurcation plots of the rental prices of two long-rental apartments and ordinary rental housing with $\alpha_{1}$, respectively, when other parameters are held constant. Red and blue bifurcation plots represent the rental prices of two long-rental apartments, $p_{1}$ and $p_{2}$, respectively. Green bifurcation plot represents the rental price $p_{s}$ for ordinary rental housing. The system is stable when $\alpha_{1}<0.438$. There are two equilibrium points of the game system when $\alpha_{1}>0.438$. As $\alpha_{1}>0.438$ increases to $\alpha_{1}>0.610$, the system begins to bifurcate in four cycles. When $\alpha_{1}>0.610$ continues to increase to $\alpha_{1}>0.615$, the system begins to bifurcate in eight cycles. The system finally enters a chaotic state with the increase of $\alpha_{1}$. When the system enters chaos, the rental price of long-rental apartment 1 and the rental price of ordinary rental housing become unpredictable and exhibit a state of violent volatility. However, when the system is in a periodic cycle as well as chaos, the rental price of long-rental apartment 2 becomes lower than when the system is in a stable state.

Figure 4(a) shows a two-dimensional bifurcation diagram of the system, which shows not only the steady state, periodic state, and chaotic state of the system, but also the path of the system from steady state to chaotic state. As 


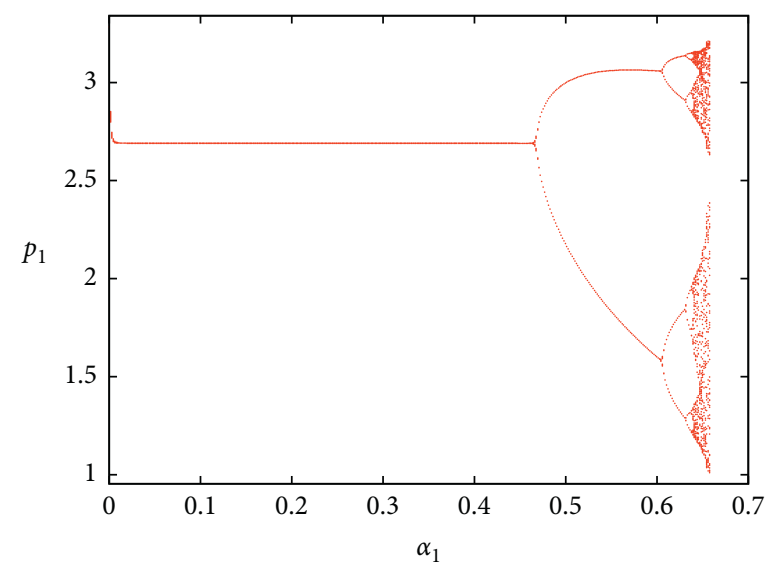

(a)

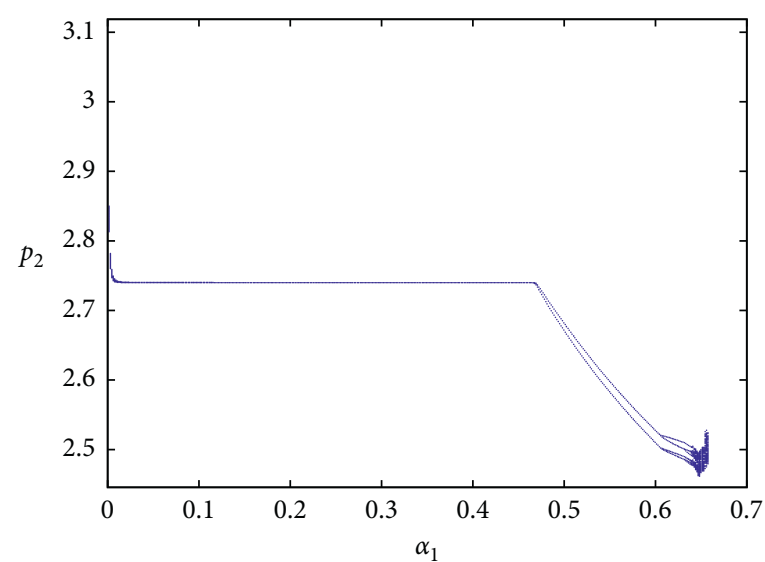

(b)

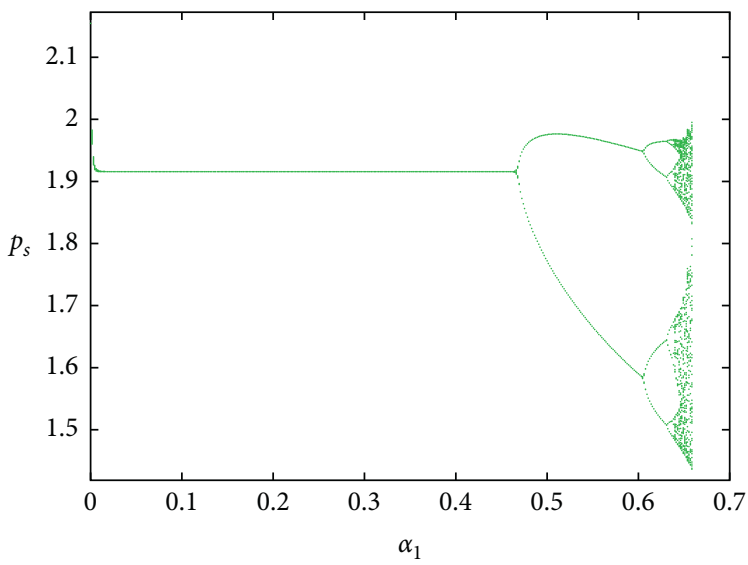

(c)

FIGURE 3: The bifurcation diagram of price with respect to $\alpha 1$, when $\alpha_{2}=0.01$.

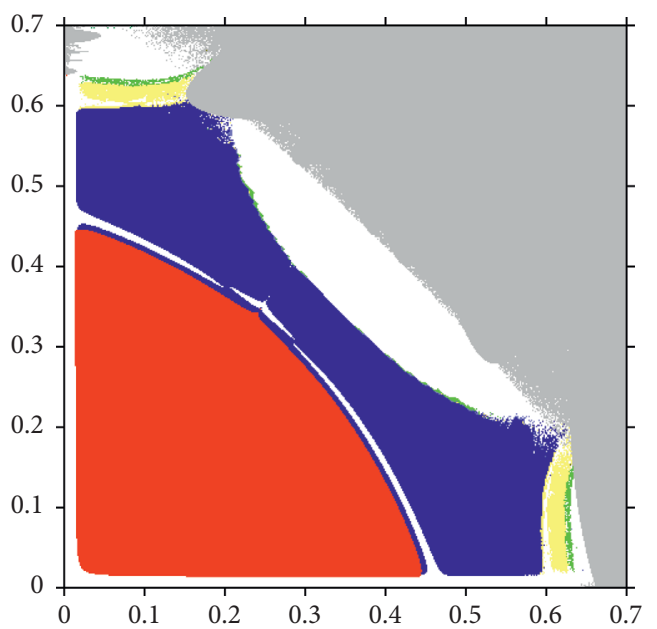

(a)

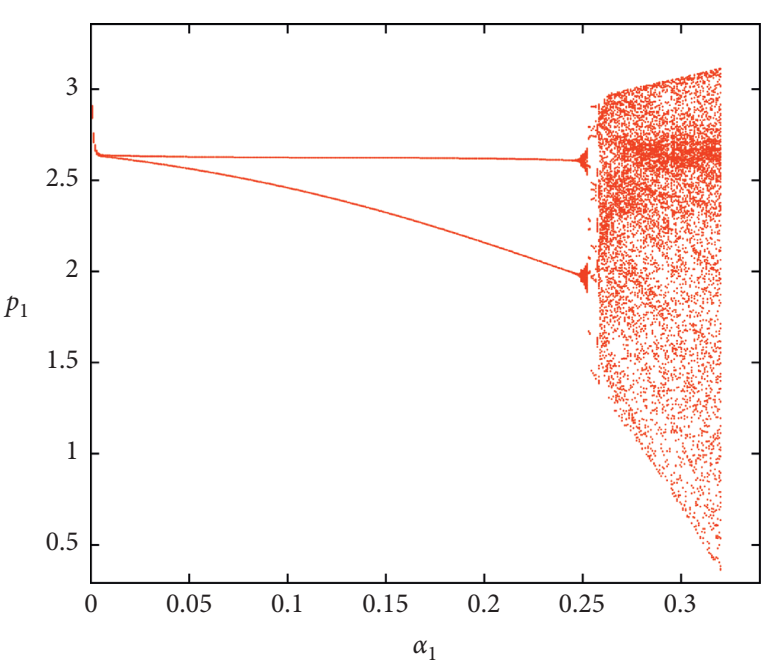

(b)

Figure 4: (a) The 2-D bifurcation diagram of the system with respect to $\alpha_{1}$ and $\alpha_{2}$. (b) The bifurcation diagram of $p_{1}$ with respect to $\alpha_{1}$, when $\alpha_{2}=0.45$.

shown in the figure, the red part, blue part, yellow part, and grey part represent the system in the two-cycle cycle state, four-cycle cycle state, eight-cycle cycle state, and chaotic state, respectively. It can be seen in Figure 4(b) that there are two paths from the steady state to the chaotic state, one of which is the red-blue-yellow-green-grey shown system 
entering the chaotic state via the flip bifurcation and the other red-blue-grey shown system entering the chaotic state via the Neimark-Sacker bifurcation.

In order to depict in detail the final state of rental prices of long-rental apartments and ordinary rental housing that evolved over time, Figure 5 gives the attractors of the system in different states. Figure 5(a) shows the steady attractor of the system in steady state at $\alpha_{1}=0.22$ and $\alpha_{2}=0.22$, which indicates that the rental prices of longrental apartments and ordinary rental housing which are always constant have evolved over time. Figure 5(b) shows the limit cycle of the system in the cyclic state at $\alpha_{1}=0.22$ and $\alpha_{2}=0.22$. It shows that the rental prices of long-rental apartments and ordinary rental housing are in a steady state of oscillation and the system is in cyclical motion when the two long-rental apartment firms adopt the price adjustment strategies of $\alpha_{1}=0.32$ and $\alpha_{2}=0.45$, respectively. Figure 5(c) shows the strange attractor of the system in a chaotic state at $\alpha_{1}=0.38$ and $\alpha_{2}=0.45$. It shows that the rental prices of long-rental apartments and ordinary rental housing are unstable when two long-rental apartment companies adopt the price adjustment strategies of $\alpha_{1}=0.38$ and $\alpha_{2}=0.45$, respectively. As can be seen from these three graphs, as the enterprise's price adjustment coefficient increases, the final rental price of long-rental apartments and ordinary rental housing exhibit an increasingly complex state.

4.2. The Impact of Landlord Reference Effect on the System. Figure 6(a) gives the stable region of the system when the landlords have different perception coefficients. The blue, purple, and pink parts represent the stable region at $\eta=0.8, \eta=0.5$, and $\eta=0.2$, respectively. The figure shows that the stability domain of the system gradually decreases with the increase of the landlord's perception coefficient. Thus, this suggests that the less reference landlords have to do price adjustments for decentralized long-term rental apartments, and the more likely it is that rents for decentralized long-term rental apartments and general rental housing will fluctuate.

To understand in more detail the impact on the system due to changes in landlords' perceptions of decentralized long-rental apartments rents adjustment, Figures 6(b)-6(d) give 3D bifurcation plots of the impact of different decentralized long-rental apartments firm 1 rents adjustment coefficients and landlords' perception coefficients on decentralized long-rental apartments rents as well as general rental housing rents. Where Figures 6(b) and 6(c) show the rents of decentralized long-term rental apartment 1 and decentralized longterm rental apartment 2, respectively, the graph shows that the equilibrium price of decentralized long-term rental apartments for rent decreases with the increase of landlords' perception coefficients. When the system is in a chaotic state caused by the price adjustment strategy of decentralized long-rental apartment 1 , the rental price fluctuations of the two decentralized long-rental apartments gradually diminish with the increase of the landlord's perception coefficient. When the system is in the cyclical state, the rental price of decentralized longrental apartments firm 2 decreases with the increase of the landlord's perception coefficient. Figure 6(d) shows the bifurcation diagram of the general rental housing rent, which shows that the equilibrium price of general rental housing decreases with the increase of the landlord's perception coefficient. When the system is in a chaotic state, the fluctuation of rent increases with the increase of the landlord's perception coefficient.

\subsection{The Impact of Demand Share of Long-Rental Apartment} Enterprise on the System. The demand share of a decentralized long-rental apartment reflects the influence of that firm in the decentralized long-rental apartment market. If the tenant has a higher demand for the properties provided by a firm in the decentralized long-rental apartment market, it means that the rental price of the house determined by that firm is more influential in the housing rental market. Figure 7(a) gives the system stability domain when decentralized long-term rental apartment firm 1 has different demand shares in the market. The purple, blue, and pink parts represent the stability domain when $\theta=0.5, \theta=0.2$, and $\theta=0.8$, respectively. This shows that the stability of the system is more stable when the demand share difference between two decentralized long-term rental apartment enterprises is small than when the demand share difference between the two in the market is large, indicating that the coexistence of two long-term rental apartment enterprises with roughly the same influence is conducive to maintaining the stability of the rental market, while the existence of two enterprises with large demand differences in a certain decentralized long-term rental apartment market makes the market more prone to instability.

In order to understand the impact of different demand shares on the system in more detail, Figures $7(\mathrm{~b})-7(\mathrm{~d})$ give the $3 \mathrm{D}$ bifurcation diagrams of the rental price as well as the take-up price of decentralized long-stay apartments for different price adjustment factors and demand shares of decentralized long-stay apartment firms 1. Among them, Figures 7(b) and 7(c) show the rental prices of decentralized long-rental apartment 1 and decentralized long-rental apartment 2, respectively. The figure shows that when the system is in a stable state, the rental price of decentralized long-rental apartment increases with the increase of the demand share of that decentralized long-rental apartment enterprise in the market. When the system is in a chaotic state caused by the price adjustment strategy of decentralized long-rental apartment 1 , the rental price fluctuations of decentralized long-rental apartment firm 1 and decentralized long-rental apartment firm 2 gradually weaken as the difference in the demand share of the two firms decreases. Figure $7(d)$ shows the take-up price, which shows that when the system is in the steady state, the take-up price increases with the increase of the difference in demand between the two decentralized long-rental apartments, and when the system is in the chaotic state caused by the price adjustment strategy of decentralized long-rental apartment 1, the 


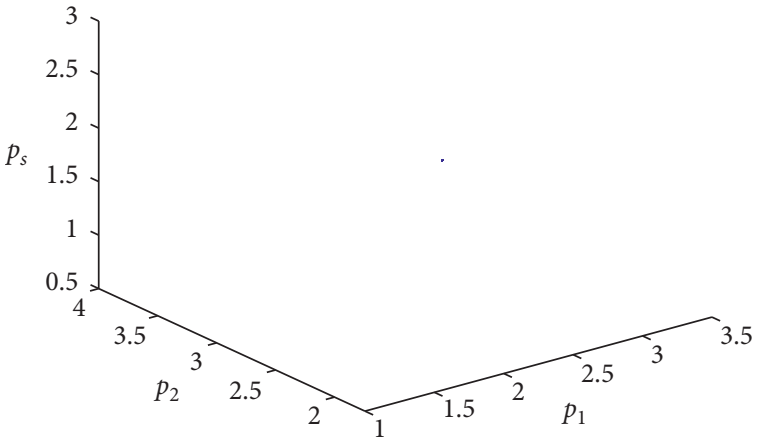

(a)

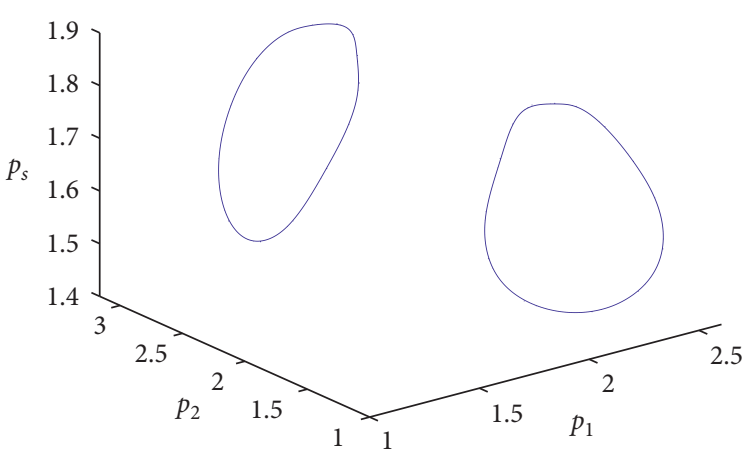

(b)

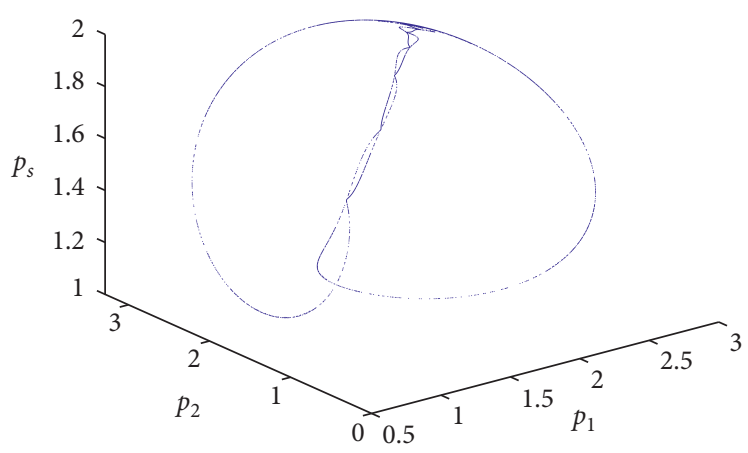

(c)

FIgURE 5: The attractor diagram of system.

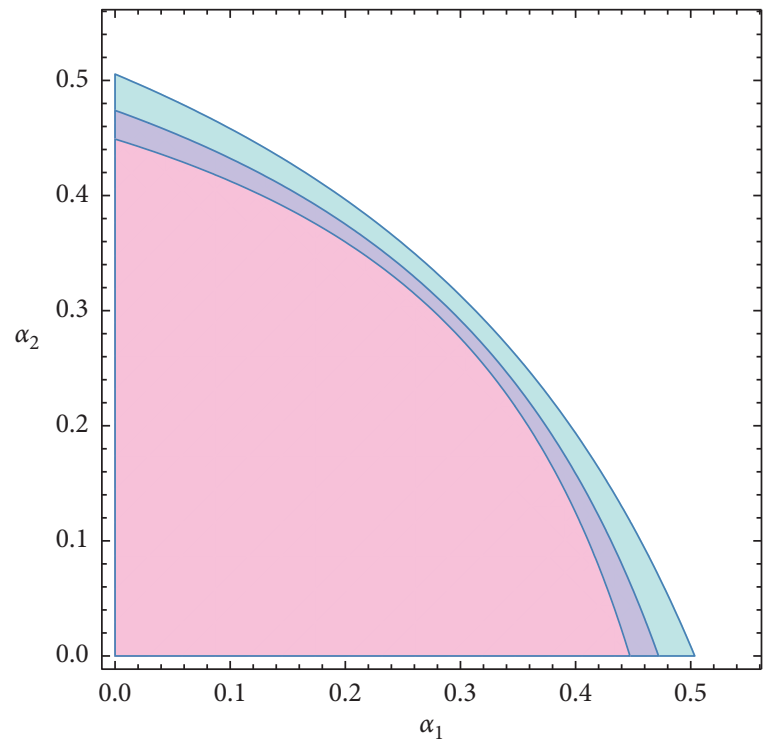

(a)

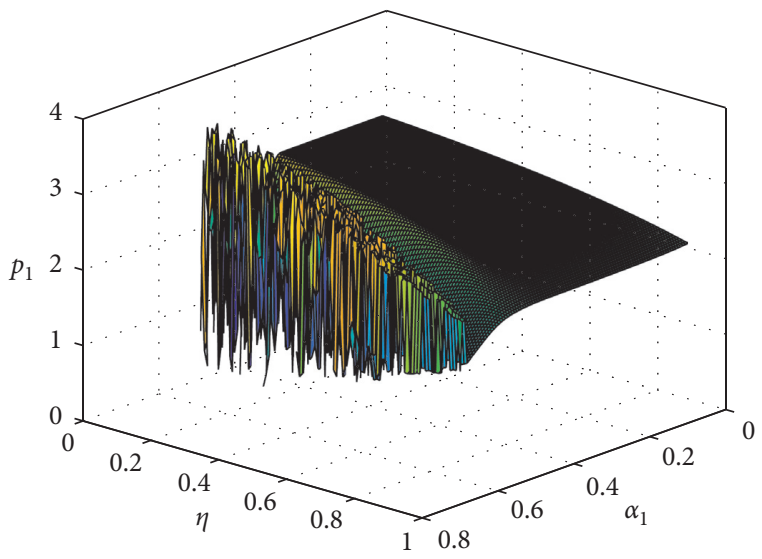

(b)

Figure 6: Continued. 


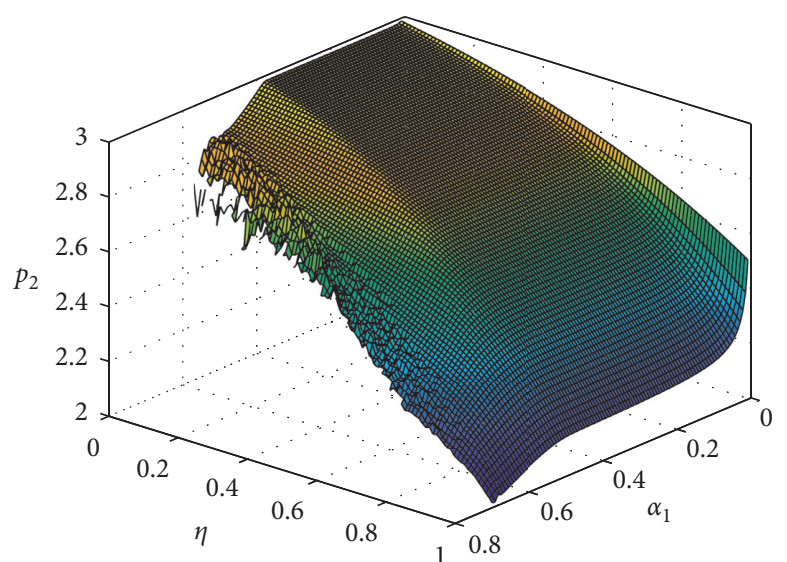

(c)

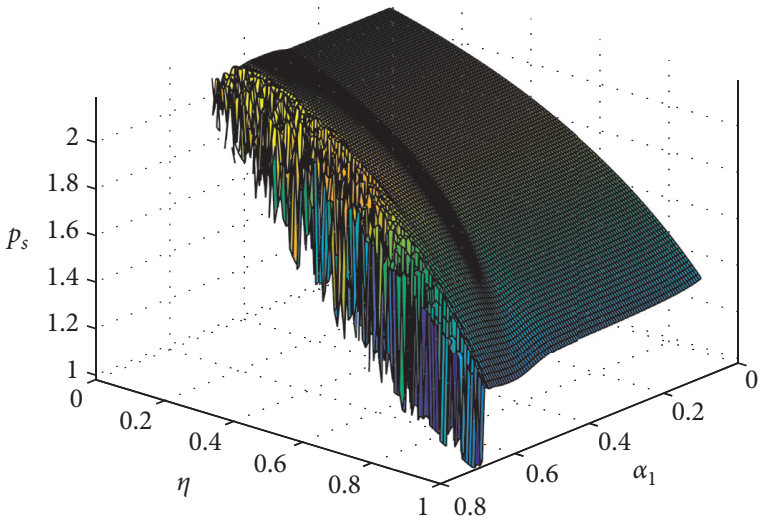

(d)

Figure 6: (a) The stability domain of the system with $\eta=0.2,0.5,0.8$. (b) The $3 \mathrm{D}$ bifurcation diagram for different combinations of $\alpha_{1}$ and $\eta$ with $\alpha_{2}=0.01((\mathrm{c})$ and $(\mathrm{d}))$.

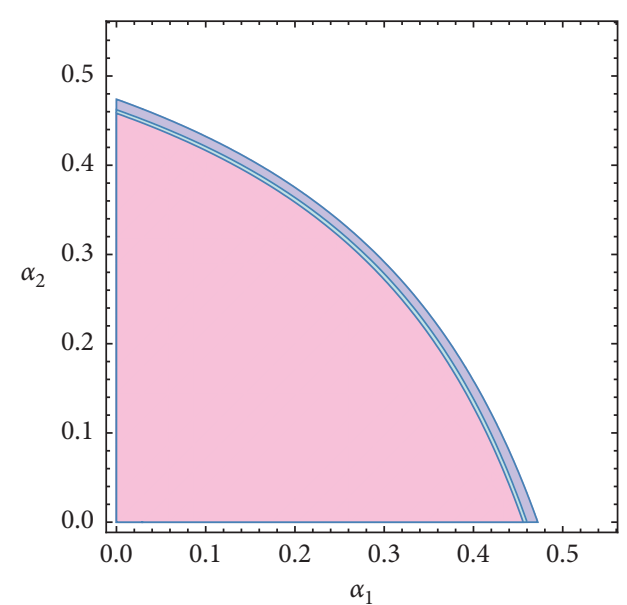

(a)

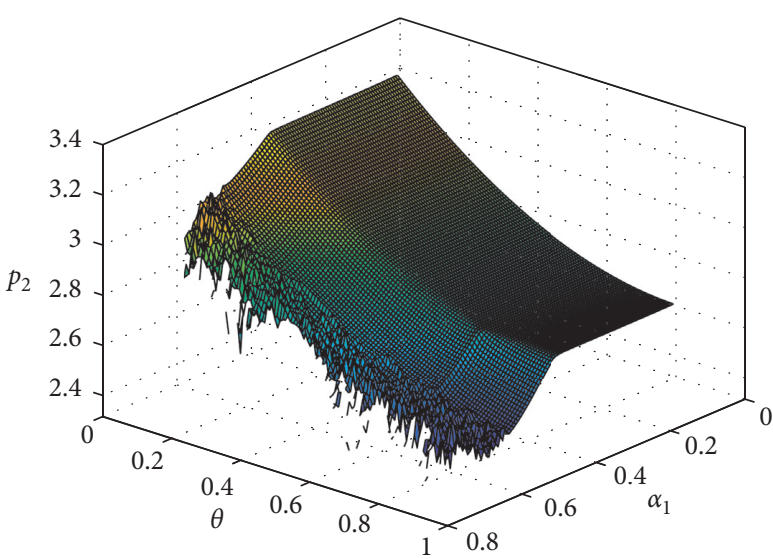

(c)

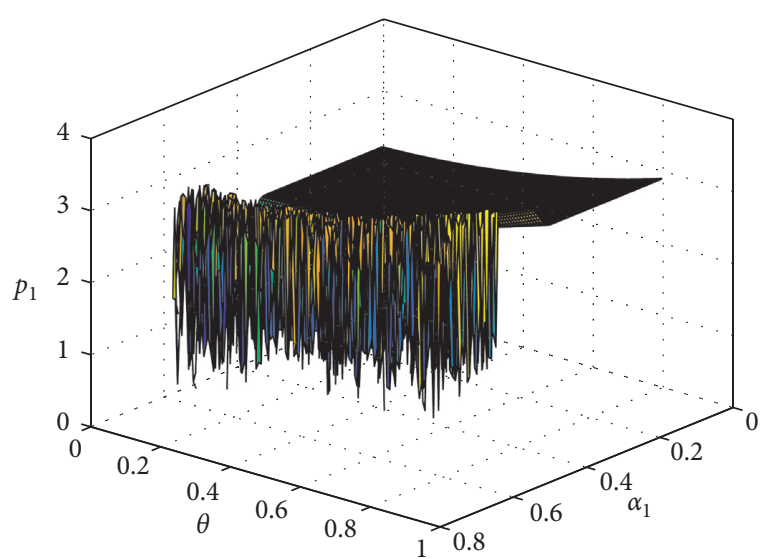

(b)

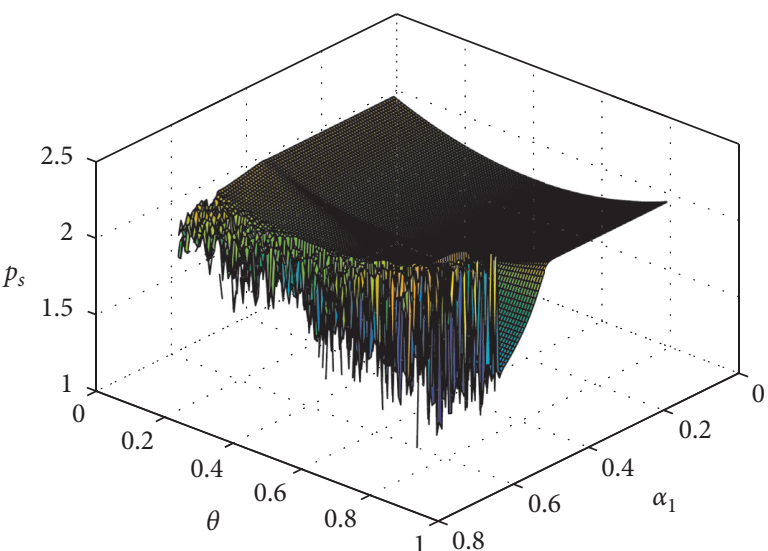

(d)

Figure 7: (a) The stability domain of the system with $\theta=0.2,0.5,0.8$. (b) The 3D bifurcation diagram for different combinations of $\alpha_{1}$ and $\theta$ with $\alpha_{2}=0.01$. ((c) and (d)).

fluctuation of the take-up price gradually increases with the increase of the demand share of decentralized long-rental apartment 1 .
4.4. The Impact of Service Level of Long-Rental Apartment Enterprise on the System. Figure 8(a) gives the stability domain of the system when the decentralized long-term 


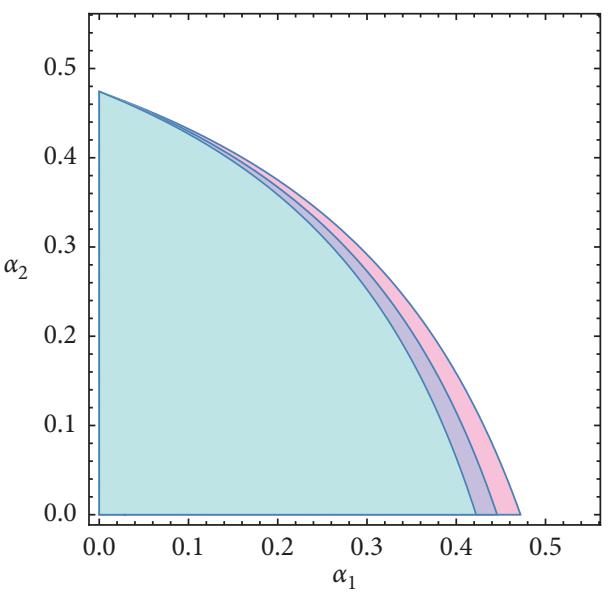

(a)

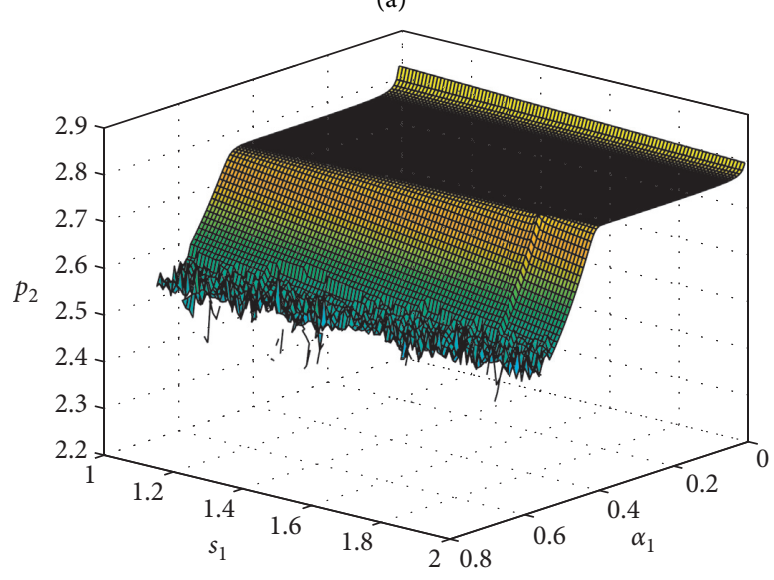

(c)

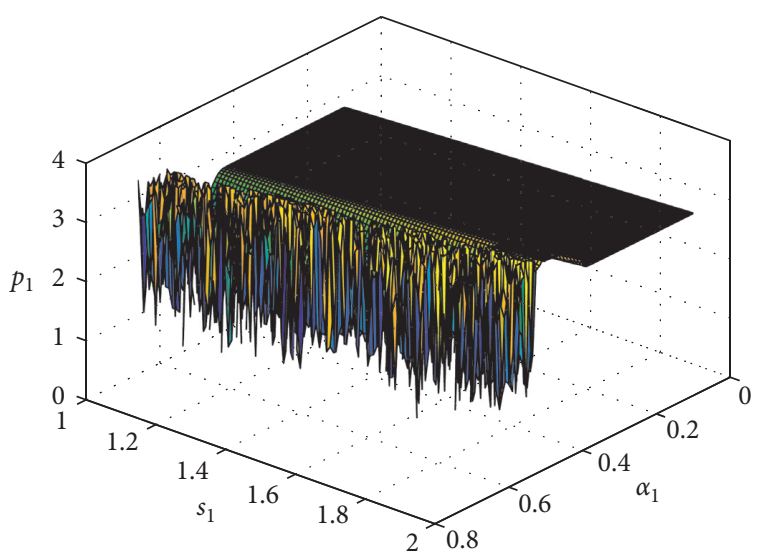

(b)

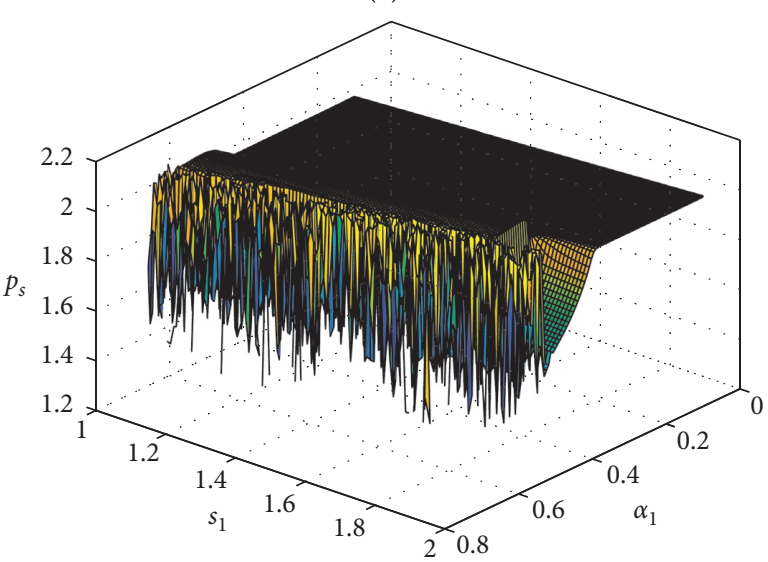

(d)

FIGURE 8: (a) The stability domain of the system with $s 1=1,1.5$, 2. (b) The 3D bifurcation diagram for different combinations of $\alpha_{1}$ and $s_{1}$ with $\alpha_{2}=0.01((\mathrm{c})$ and $(\mathrm{d}))$.

rental apartment firms adopt different service standards. The blue, purple, and pink parts represent the stability domain when $s_{1}=1, s_{1}=1.5$, and $s_{1}=2$, respectively. The figure shows that the stability domain of the system increases gradually as the service level of a decentralized long-term rental apartment in the market increases. Thus, it shows that the more decentralized long-term rental apartment companies adopt the strategy of increasing the service level, the easier it is for the rent of decentralized long-term rental apartments as well as the rent of ordinary rental housing to maintain a stable state.

In order to understand in more detail the impact of decentralized long-term rental apartment enterprises adopting the strategy of changing service level on the system, Figures $8(\mathrm{~b})-8(\mathrm{~d})$ give the $3 \mathrm{D}$ bifurcation diagrams of the rents of general rental housing and each decentralized longterm rental apartment when decentralized long-term rental apartment enterprise 1 has different price adjustment factors and service standards. Figure 8 shows that the equilibrium prices of both decentralized long-term rental apartments as well as general rental housing increase as the service level of decentralized long-term rental apartment enterprises increases. The service level of the decentralized long-term rental apartment firms only changes the stability domain of the system and does not change the volatility of the price when the system is in a chaotic state.

\section{Conclusion}

Through the reasoning analysis of the price adjustment strategies of the two decentralized long-stay apartments, the game system can easily remain in a stable state as long as the two long-stay apartment enterprises adopt smaller price adjustment coefficients, and as long as one of them increases the price adjustment coefficients, the system gradually destabilizes and then bifurcates by the enterprises gradually increasing the price adjustment coefficients.

Based on the discussion of the price adjustment coefficient of enterprises, numerical simulation is used to discuss the influence of landlord reference effect, demand share of decentralized long-term rental apartments, and service quality of long-term rental apartments on the system, respectively. It is found that these three factors not only affect the rental prices of two decentralized long-term rental apartment enterprises and the equilibrium prices of general rental housing but also have different effects on the stability 
and volatility of prices. Reference effect of landlords can mitigate the systemic stability of the firms' price adjustment coefficients, and it can also reduce the volatility of the rental prices of the two decentralized long-stay apartment firms, especially for the firms with larger price adjustment strategies, but it can increase the volatility of the rental prices of general rental housing. As for the influence factor of demand share, the difference of demand share of two decentralized long-term rental apartments becomes the main reason to influence the system, in which the game system is more likely to remain stable when the difference of demand share of two long-term rental apartment enterprises in the market is small, but the game dynamics system is more likely to be destabilized when the difference between them is large. In terms of influencing the volatility of the system, the smaller the difference between the demand shares of the two firms, the less volatile the rental prices of the two firms, while the rental prices of ordinary rental housing will become more volatile due to the increase in the demand share in the market of the firm that takes a larger price adjustment factor. However, the change in service quality does not affect the volatility of rental prices of decentralized long-term rental apartments and general rental housing but only changes the stability of the system; i.e., the stability of the system is enhanced by the increase in service quality.

\section{Data Availability}

All data used to support the findings of this study are included within the article.

\section{Conflicts of Interest}

The authors declare that they have no conflicts of interest.

\section{Acknowledgments}

The research was supported by the National Natural Science Foundation of China (no. 71904042).

\section{References}

[1] S. Liu, S. Long, and Y. Liu, "Long-stay apartment dynamics, problems and their related countermeasures," Decisionmaking and information, vol. 2018, no. 1, pp. 71-76, 2019.

[2] Z. Li, W. Yang, and L. Ma, "Forty years of reform of China's urban housing system," Economic Theory and Economic Management, vol. 2018, no. 12, pp. 5-23, 2018.

[3] J. Chen, "Promoting the construction of the housing system with supply-side reform: "Houses are not for speculation," China Development, vol. 17, no. 15, pp. 13-18, 2017.

[4] J. Qiu, "The game of social forces participating in the evolution of the housing rental market and government regulation," American Journal of Industrial and Business Management, vol. 10, no. 1, pp. 99-109, 2020.

[5] Z. Yue, "Solving the housing rental market development dilemma," China Finance, vol. 2019, no. 24, pp. 74-75, 2019.

[6] Y. Pang and H. Liu, "Are rent levels higher for distributed long term rentals?” China Real Estate, vol. 2019, no. 15, pp. 18-22, 2019.
[7] G. J. Stigler, “A theory of oligopoly," Journal of Political Economy, vol. 72, no. 1, pp. 44-61, 1964.

[8] M. Kopel, "Simple and complex adjustment dynamics in Cournot duopoly models," Chaos Solitons \& Fractals, vol. 7, no. 12, pp. 2031-2048, 1991.

[9] T. N. Puu, "On the stability of cournot equilibrium when the number of competitors increases," Journal of Economic Behavior \& Organization, vol. 6, no. 3-4, pp. 445-456, 2008.

[10] E. Ahmed and M. F. Elettreby, "Controls of the complex dynamics of a multi-market Cournot model," Economic Modelling, vol. 37, pp. 251-254, 2014.

[11] F. Cavalli and A. Naimzada, "A Cournot duopoly game with heterogeneous players: nonlinear dynamics of the gradient rule versus local monopolistic approach," Applied Mathematics and Computation, vol. 249, pp. 382-388, 2014.

[12] W. A. Brock, C. H. Hommes, and F. O. O. Wagener, "Evolutionary dynamics in markets with many trader types," Journal of Mathematical Economics, vol. 41, no. 1-2, pp. 7-42, 2005.

[13] R. Diecia and F. Westerhoff, "Stability analysis of a cobweb model with market interactions," Applied Mathematics \& Computation, vol. 215, no. 6, pp. 2011-2023, 2009.

[14] Y. Fan, T. Xie, and J. Du, "Complex dynamics of duopoly game with heterogeneous players: a further analysis of the output model," Applied Mathematics and Computation, vol. 218, no. 15, pp. 7829-7838, 2012.

[15] J. Ma and L. Mu, "Dynamic analysis of the game between land supply and housing prices," International Journal of Computer Mathematics, vol. 85, no. 6, pp. 983-992, 2008.

[16] J. Ma and J. Zhang, "Research on the price game and the application of delayed decision in oligopoly insurance market," Nonlinear Dynamics, vol. 70, no. 4, pp. 2327-2341, 2012.

[17] A. Sambas, S. He, H. Liu et al., "Dynamical analysis and adaptive fuzzy control for the fractional-order financial risk chaotic system," Advances in Difference Equations, vol. 2020, no. 1, pp. 1-12, 2020.

[18] L. Zhao, J. Chang, and J. Du, "Dynamics analysis on competition between manufacturing and remanufacturing in context of government subsidies," Chaos, Solitons \& Fractals, vol. 121, pp. 119-128, 2019.

[19] H. B. Hwarng and N. Xie, "Understanding supply chain dynamics: a chaos perspective," European Journal of Operational Research, vol. 184, no. 3, pp. 1163-1178, 2008.

[20] F. Zhang and C. Wang, "Dynamic pricing strategy and coordination in a dual-channel supply chain considering service value," Applied Mathematical Modelling, vol. 54, pp. 722-742, 2017.

[21] Y. Wu and D. Z. Zhang, "Demand fluctuation and chaotic behaviour by interaction between customers and suppliers," International Journal of Production Economics, vol. 107, no. 1, pp. 250-259, 2007.

[22] Y. Huang, X. Chen, Q. Li, and X. Ma, "The complexity and entropy analysis for service game model based on different expectations and optimal pricing," Entropy, vol. 20, no. 11, 2018.

[23] J. Ma, W. Di, and H. Ren, "Complexity dynamic character analysis of retailers based on the share of stochastic demand and service," Complexity, vol. 2017, pp. 1-12, 2017.

[24] A. Dixit, "Comparative statics for oligopoly," International Economic Review, vol. 27, no. 1, pp. 107-122, 1986. 